\title{
Matéria
}

ISSN 1517-7076

Revista Matéria, v. 12, n. 1, pp. 44 - 53, 2007

http://www.materia.coppe.ufrj.br/sarra/artigos/artigo10733

\section{Influência do Substrato nas Propriedades Estruturais e Morfológicas de Filmes de Manganita de Lantânio Dopados com Estrôncio Depositados por Spray-Pirólise}

Sarah dos Santos Rabelo ${ }^{1}$, Selma Aparecida Venâncio ${ }^{1}$, Herval Ramos Paes Jr$^{1}$, Gilmar Clemente Silva², Paulo Emílio Valadão de Miranda ${ }^{2}$

\section{${ }^{1} \mathrm{LAMAV/CCT/UENF}$}

Av. Alberto Lamego, 2000, Horto, Campos dos Goytacazes, RJ. CEP: 28013-602

e-mail: sarah@uenf.br, selma@uenf.br, herval@uenf.br

${ }^{2}$ Laboratório de Hidrogênio - Labh2 - PEMM/COPPE/UFRJ

CP: 68505. Ilha do Fundão, Rio de Janeiro, RJ. CEP: 21941-972

e-mail: gilmar@labh2.coppe.ufrj.br, pmiranda@labh2.coppe.ufrj.br

\section{RESUMO}

Neste trabalho foram preparados filmes de manganita de lantânio dopados com estrôncio (LSM) nas concentrações de 0, 20 e 40 \%at. depositados sobre substratos de silício monocristalino (100) tipo p e de zircônia estabilizada com ítria 8 \% em mol (8ZEI) utilizando a técnica de spray-pirólise, tendo como objetivo principal sua utilização como catodo em pilhas a combustível de óxido sólido (PaCOS). Os filmes foram termicamente tratados a 900 ou $1000^{\circ} \mathrm{C}$ por duas horas em atmosfera ambiente, tendo sido caracterizados estrutural e morfologicamente pelas técnicas de difração de raios X (DRX) e microscopia eletrônica de varredura (MEV), respectivamente. Os resultados obtidos por MEV revelaram que o tipo de substrato tem grande influência na microestrutura dos filmes. Os filmes depositados em substratos de silício e tratados termicamente tendem a apresentar grande quantidade de trincas. Este fato se deve a incompatibilidade térmica entre filme e substrato, ocasionada pela grande diferença dos respectivos coeficientes de expansão térmica. Os filmes depositados sobre substratos de 8ZEI, além de apresentar maior uniformidade, se mostraram mais aderentes ao substrato. A análise das estruturas cristalográficas dos filmes de LSM tratados termicamente comprova a formação da fase cristalina referente à estrutura da perovskita.

Palavras chaves: Spray-pirólise, filme, LSM, PaCOS, catodo

\section{Influence of the Substrate type on Structural and Morphological Properties of Sr-doped Lanthanum Manganite Films Deposited by Spray-Pyrolysis}

\section{ABSTRACT}

Lanthanum manganite films doped with strontium (LSM) were deposited by spray-pyrolysis on ptype monocrystalline silicon (100) and yttria stabilized zirconia (YSZ) 8mol\% substrates, aiming their application as cathode in solid oxide fuel cells (SOFC). The films were heat treated in air at 900 or $1000^{\circ} \mathrm{C}$ for two hours and the structural and morphological properties were investigated using X-ray diffraction (XRD) and scanning electron microscopy (SEM). The results obtained by SEM revealed that the substrate type has great influence on the film microstructure. SEM images of the heat-treated films deposited on silicon substrates tend to present a great amount of cracks. This result is related with the thermal incompatibility between film and substrate, caused by the great difference of the respective thermal expansion coefficients. For films deposited on YSZ substrates better uniformity and adherence were observed. X-ray diffraction patterns of the thermal treated films revealed peaks corresponding to the perovskite structure.

Keywords: Spray-pyrolysis, film, LSM, SOFC, cathode 


\section{INTRODUÇÃO}

O estudo das manganitas de lantânio na forma de filmes abrange uma diversificada área de aplicações tecnológicas, tais como catalisadores, semicondutores cerâmicos e, mais recentemente, seu emprego como catodo de pilhas a combustível. Materiais do tipo $\operatorname{Ln}_{1-\mathrm{x}} \mathrm{A}_{\mathrm{x}} \mathrm{MnO}_{3}$ ( $\mathrm{Ln}=$ lantanídeos, $\mathrm{A}=$ cátions bivalentes como $\mathrm{Ca}$, Sr, Mg) têm sido objetos de interessantes pesquisas desde 1993 quando da descoberta da magnetorresistência colossal (MRC), o que lhes permite o uso em dispositivos de sensores de campo magnético e elétrico em discos rígidos de computadores [1]]. Neste último caso os filmes de LSM devem ser depositados sobre substratos de Si monocristalino.

Uma série de métodos é empregada na deposição de filmes de manganitas intrínsecos e dopados [2]]. As técnicas mais conhecidas são pulverização catódica, ablação a laser, serigrafia, entre outros. A técnica de spray-pirólise foi utilizada neste trabalho devido à sua praticidade, baixo custo e capacidade de produção [్, $\underline{4}, \underline{5}]$.

Neste estudo, substratos comerciais de silício monocristalino tipo p, Si (100), e de zircônia estabilizada com ítria 8\% em mol (8ZEI) foram empregados na deposição de filmes da série $\mathrm{La}_{1-\mathrm{x}} \mathrm{Sr}_{\mathrm{x}} \mathrm{MnO}_{3}$ $\operatorname{com} x=0,0,2$ e 0,4 . As amostras foram submetidas a tratamentos térmicos a $900^{\circ} \mathrm{C}$ e a $1000^{\circ} \mathrm{C}$ por um período de 2 horas em atmosfera ambiente.

Os efeitos da temperatura de tratamento térmico, da concentração de dopante, e do tipo de substrato nas propriedades estruturais e morfológicas foram investigados pelas técnicas de raios $\mathrm{X}$ e microscopia eletrônica de varredura, respectivamente.

\section{MATERIAIS E MÉTODOS}

Como já citado, foram obtidos filmes de manganita de lantânio dopados com estrôncio nas concentrações de 0, 20 e 40\%at. em substratos de Si (100) e 8ZEI utilizando os recursos da técnica de spraypirólise.

A solução precursora foi preparada utilizando nitrato de lantânio hexa-hidratado $\left(\mathrm{La}\left(\mathrm{NO}_{3}\right) \cdot 6 \mathrm{H}_{2} \mathrm{O}\right)$ e sulfato de manganês mono-hidratado $\left(\mathrm{MnSO}_{4} \cdot \mathrm{H}_{2} \mathrm{O}\right)$, e o dopante cloreto de estrôncio hexa-hidratado $\left(\mathrm{SrCl}_{2} \cdot 6 \mathrm{H}_{2} \mathrm{O}\right)$, dissolvidos, separadamente, em água deionizada, com concentrações de 0,025M. Estas soluções foram então misturadas segundo as proporções em estudo e colocadas em um reservatório que alimenta o bico atomizador.

A técnica de spray-pirólise pode ser descrita pelo seguinte procedimento: sobre os substratos colocados em uma chapa aquecida por uma resistência elétrica, incide um spray, da solução preparada, formado por um gás de arraste (ar) e com o fluxo controlado por uma válvula na saída do reservatório. O spray entra em contato com os substratos aquecidos, ocorrendo vaporização dos compostos voláteis da solução e conseqüente decomposição química dos elementos na superfície do substrato, resultando no filme de LSM. Os parâmetros de deposição empregados neste trabalho são descritos na Tabela 1.

Tabela 1: Descrição dos parâmetros de deposição adotados.

\begin{tabular}{|c|c|}
\hline Parâmetro & Valor \\
\hline Distância entre bico e substrato (d) & $35 \mathrm{~cm}$ \\
\hline Fluxo da solução $\left(\phi_{\mathrm{S}}\right)$ & $\begin{array}{c}1,5 \mathrm{ml} / \mathrm{min}-8 Z \mathrm{EI} \\
3,0 \mathrm{ml} / \mathrm{min}-\mathrm{Si}(100)\end{array}$ \\
\hline Pressão do gás de arraste $\left(\mathrm{P}_{\mathrm{g}}\right)$ & $1,5 \mathrm{Kgf} / \mathrm{cm}^{2}$ \\
\hline Temperatura dos substratos $\left(\mathrm{T}_{\mathrm{s}}\right)$ & $400^{\circ} \mathrm{C}$ \\
\hline Tempo de deposição $\left(\mathrm{t}_{\mathrm{d}}\right)$ & $\begin{array}{c}20 \mathrm{~min}-8 \mathrm{ZZEI} \\
60 \mathrm{~min}-\mathrm{Si}(100)\end{array}$ \\
\hline Concentração da solução precursora (C) & $0,025 \mathrm{M}$ \\
\hline
\end{tabular}

Após a deposição dos filmes, estes são submetidos a um pré-tratamento térmico à temperatura de $500^{\circ} \mathrm{C}$ durante $30 \mathrm{~min}$, uma vez que seu resfriamento imediato resulta num material com aspecto gelatinoso. Cada conjunto de amostras representativo do tipo de substrato (Si ou ZEI) e concentração de dopante (0, 20 ou $40 \%$ at.) foi tratado termicamente nas temperaturas de 900 e $1000^{\circ} \mathrm{C}$, respectivamente. Os tratamentos foram realizados utilizando um forno mufla marca EDG modelo 3P por um período de 2 horas em atmosfera ambiente. $\mathrm{O}$ tratamento térmico determina as mais importantes características dos filmes.

A técnica de difração de raios X permitiu a investigação das estruturas cristalográficas dos filmes e a identificação das fases presentes. O difratômetro marca Shimadzu, modelo XRD6000 utilizado operou com comprimento de onda de $1,54 \AA$, passo em $\theta$ de $0,05^{\circ}$, tempo de contagem igual a 5 s e $2 \theta$ entre $20^{\circ}$ e $80^{\circ}$. 
A investigação da morfologia e microestrutura dos filmes foi realizada utilizando-se o microscópio eletrônico de varredura (MEV) marca Zeiss modelo 940-A operando com elétrons secundários e voltagem de feixe de elétrons entre 10 e $20 \mathrm{kV}$.

\section{RESULTADOS E DISCUSSÃO}

\subsection{Caracterização Estrutural}

As Figuras 1 e 2 mostram os difratogramas de raios $\mathrm{X}$ obtidos para os filmes depositados em substratos de silício e 8ZEI, respectivamente. Os resultados revelam que os tratamentos térmicos propiciaram a formação das fases esperadas, referentes à estrutura da perovskita. Além disso, nos filmes depositados em 8ZEI, foram detectados picos referentes aos substratos de zircônia, sendo mais intensos nos filmes tratados a $1000^{\circ} \mathrm{C}$. Em anexo a estes difratogramas encontram-se, para comparação, os padrões referentes à $\mathrm{La}_{0,8} \mathrm{Sr}_{0,2} \mathrm{MnO}_{3}$ e ao substrato 8ZEI dos arquivos JCPDS 40-1100 e 48-0224, respectivamente.

No filme de $\mathrm{La}_{0,6} \mathrm{Sr}_{0,4} \mathrm{MnO}_{3}$ depositado em silício e tratado a $1000^{\circ} \mathrm{C}$, além das fases da perovskita, foram detectados picos referentes às fases $\mathrm{La}_{2} \mathrm{O}_{3}$ e $\mathrm{MnO}$, que são indesejáveis na estrutura dos filmes. Este efeito foi também observado por GAUDON et. al. [6], podendo estar relacionado ao raio iônico do cátion substituto e à elevada concentração de Sr. Além disso, na estrutura da perovskita $\mathrm{LaMnO}_{3}$, o número de coordenação do íon $\mathrm{La}^{3+}$ é 12 com raio iônico de 1,46Å, enquanto que o íon $\mathrm{Sr}^{2+}$ em substituição tem raio de $1,54 \AA$, o qual é bem maior que outros alcalinos terrosos como o $\mathrm{Ca}^{2+}(1,40 \AA)$.

\subsection{Caracterização Morfológica}

As Figuras 3 e 4 mostram, respectivamente, as imagens de MEV do topo e seção transversal dos filmes depositados em silício e tratados termicamente a 900 e $1000^{\circ} \mathrm{C}$. As micrografias revelam filmes com aparente porosidade, aspecto homogêneo e espessura de aproximadamente $5 \mu \mathrm{m}$, que seria apropriada na aplicação como catodo em pilhas a combustível de óxido sólido para operação em temperaturas intermediárias. Foram observadas várias trincas ao longo dos filmes, o que pode ser explicado pela diferença do coeficiente de expansão térmica entre o filme de LSM e o substrato de $\mathrm{Si}$, que são $13,0 \times 10^{-6} \mathrm{e}$ $4,2 \times 10^{-6} / \mathrm{K}$, respectivamente [7]. Outros problemas observados foram a presença de aglomerados de partículas em alguns filmes e pouca aderência ao substrato. Este último pode ser observado na micrografia da seção transversal pela falta de continuidade na interface filme/substrato. Entretanto, as imagens sugerem uma distribuição uniforme de tamanhos de grãos.

As Figuras 5 e 6 mostram, respectivamente, as superfícies e seções transversais dos filmes de LSM depositados em substratos de 8ZEI tratados termicamente a $900^{\circ} \mathrm{C}$ e as superfícies com diferentes aumentos dos filmes de LSM depositados em $8 Z E I$, tratados a $1000^{\circ} \mathrm{C}$. Verifica-se que os filmes intrínsecos apresentam maior concentração de trincas e maior densidade que os demais, tendo uma espessura aproximada de 3,14 $\mu \mathrm{m}$. Em escala macroscópica é possível observar indicações de que os filmes depositados sobre 8ZEI apresentam uma diminuição na quantidade de trincas em relação aos filmes depositados sobre Si, uma vez que o coeficiente de expansão térmica da 8ZEI é da ordem de 10,0 x 10 $0^{-6} / \mathrm{K}$ [8]. Outra importante observação é que os filmes têm uma estrutura porosa com superfície uniforme e lisa, boa aderência ao substrato de todos os filmes obtidos, visto que a interface filme/substrato é contínua.

Entretanto, estes filmes apresentam, ainda, uma quantidade considerável de trincas. Assim, novos testes foram realizados visando resolver este problema. Anteriormente ao procedimento de deposição, os substratos foram aquecidos lentamente até à temperatura de $400^{\circ} \mathrm{C}$ e o processo de resfriamento, após a deposição, foi igualmente controlado. O tratamento térmico também operou com taxas de aquecimento e resfriamento lentas, a $3^{\circ} \mathrm{C} / \mathrm{min}$ (os filmes anteriores foram termicamente tratados com taxa de aquecimento de $15^{\circ} \mathrm{C} / \mathrm{min}$ ). Os resultados obtidos mostraram que tal procedimento propiciou a formação de filmes isentos de trincas.

A Figura 7 mostra a superfície e secção transversal do filme de LSM depositado em substrato de 8ZEI com fluxo de 1,0 ml/min. Verifica-se que o filme é isento de trincas, com uma microestrutura bastante porosa e com distribuição uniforme. Outra importante observação é que os filmes apresentam superfície uniforme e interface filme/substrato aderente.

A Figura 8 apresenta a seção transversal do filme LSM depositado com fluxo de 1,5 ml/min. O filme é bem aderente ao substrato com espessura aproximada de $20 \mu \mathrm{m}$ apresentando maior rugosidade em relação ao filme depositado com fluxo de $1,0 \mathrm{ml} / \mathrm{min}$.

A partir destes resultados obtidos observa-se que o controle dos parâmetros de deposição e os processos de tratamento térmicos são de fundamental importância para a obtenção de filmes de $\mathrm{La}_{1-\mathrm{x}} \mathrm{Sr}_{\mathrm{x}} \mathrm{MnO}_{3}$ com características adequadas à aplicação como catodo em PaCOS. 

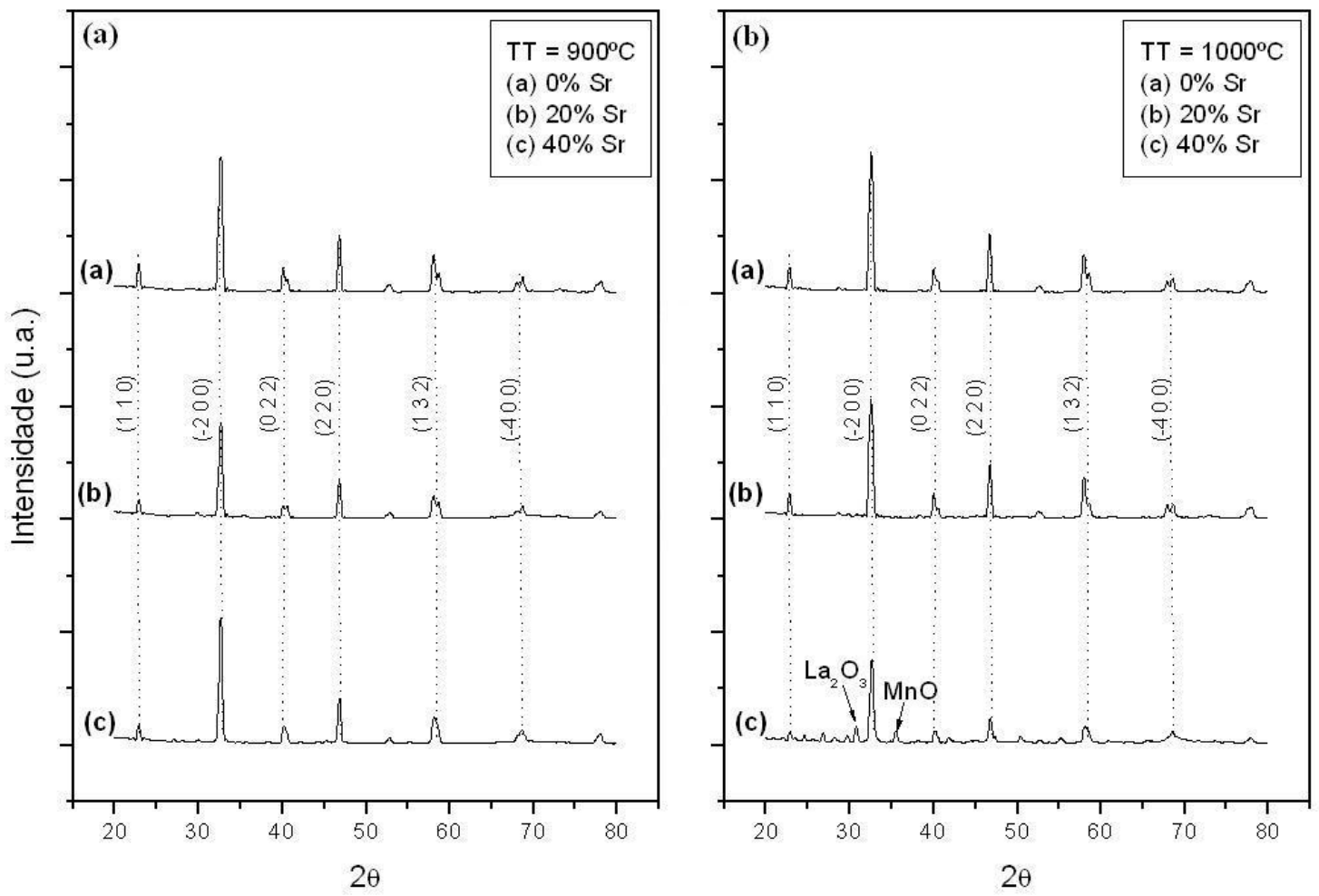

Figura 1: Difratogramas de raios X de filmes de LSM depositados em substratos de Si (100) tipo $p$ e tratados termicamente às temperaturas de: (a) 900 e (b) $1000^{\circ} \mathrm{C}$.
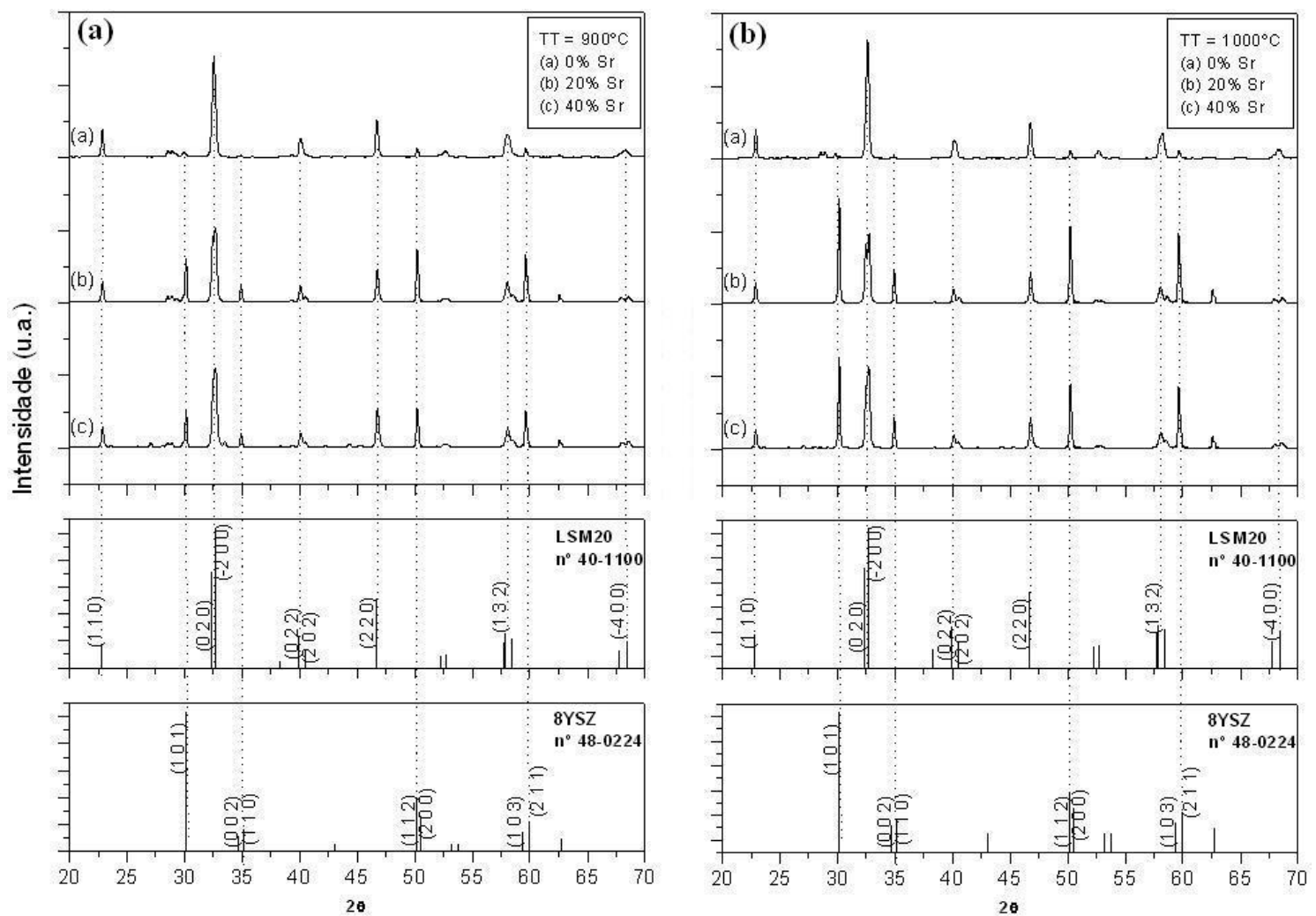

Figura 2: Difratogramas de raios X de filmes de LSM depositados em substratos de 8ZEI e tratados termicamente às temperaturas de: (a) 900 e (b) $1000^{\circ} \mathrm{C}$. 

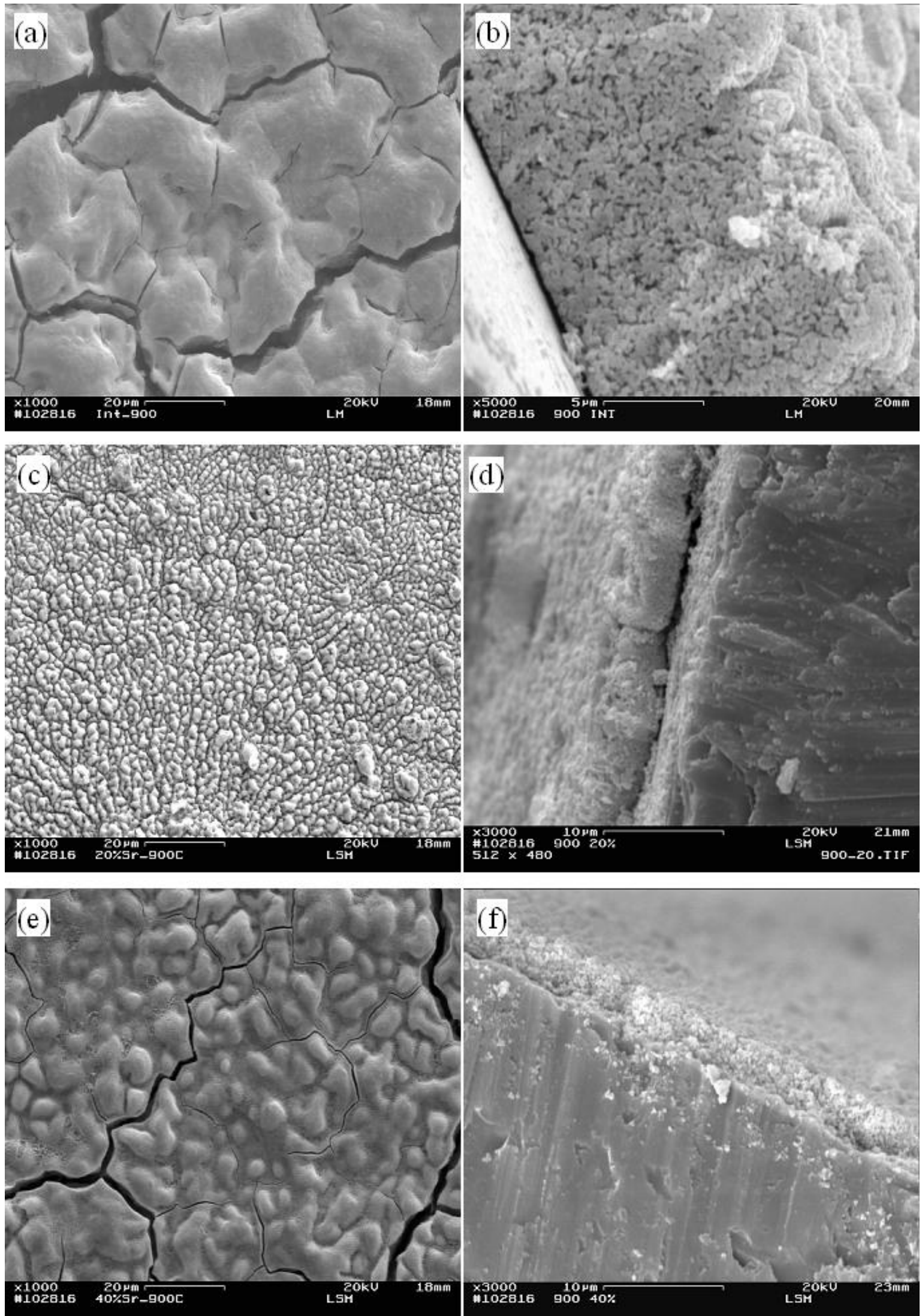

Figura 3: Imagens de microscopia eletrônica de varredura da superfície e seção transversal de filmes de LSM depositados em Si (100) tipo $p$ e tratados termicamente a $900^{\circ} \mathrm{C}$ : (a, b) $\mathrm{LaMnO}_{3}$, (c, d) $\mathrm{La}_{0,8} \mathrm{Sr}_{0,2} \mathrm{MnO}_{3}$ e (e, f) $\mathrm{La}_{0,6} \mathrm{Sr}_{0,4} \mathrm{MnO}_{3}$. 

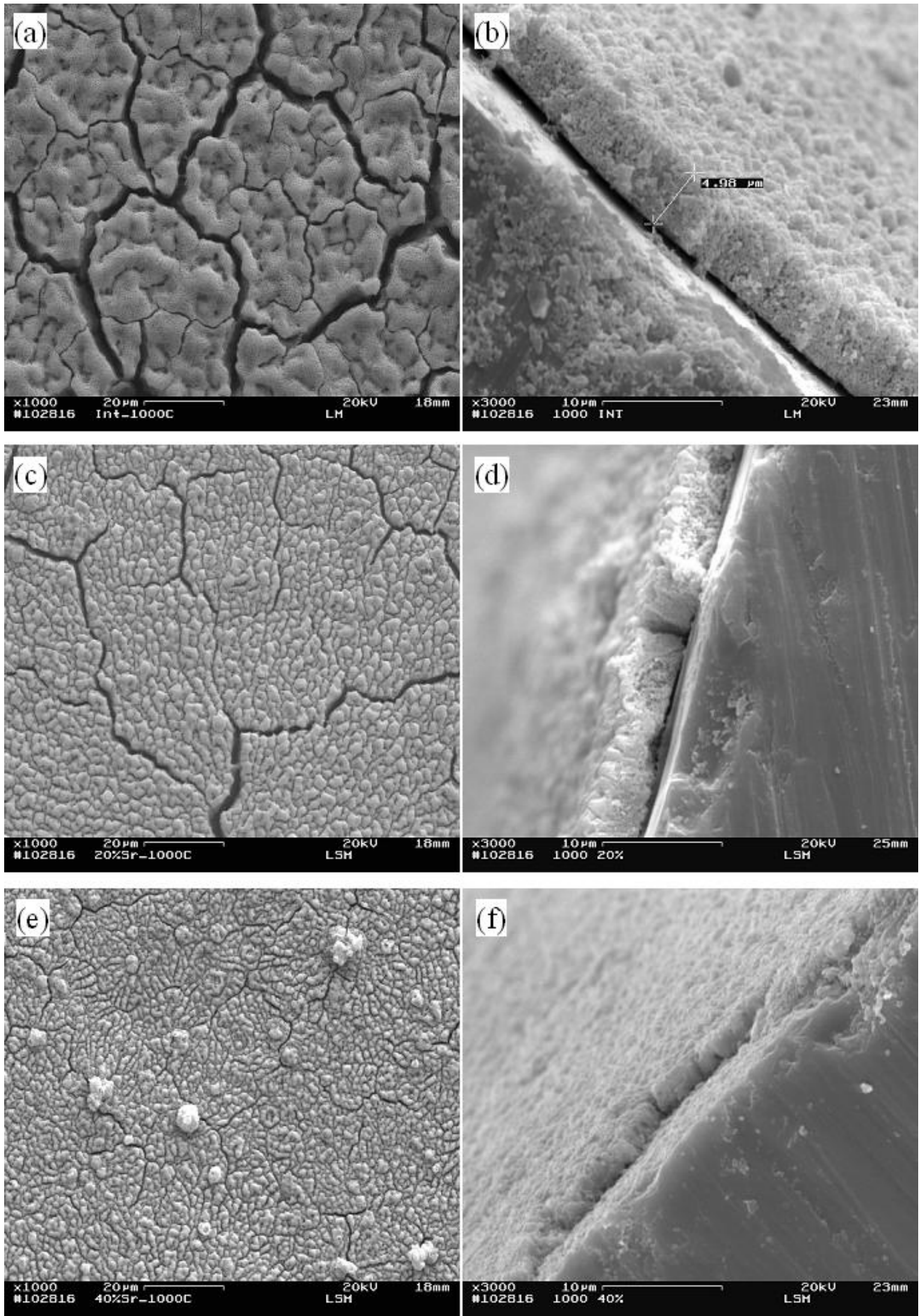

Figura 4: Imagens de microscopia eletrônica de varredura da superfície e seção transversal de filmes de LSM depositados em $\mathrm{Si}(100)$ tipo $p$ e tratados termicamente a $1000^{\circ} \mathrm{C}$ :

(a, b) $\mathrm{LaMnO}_{3}$, (c, d) $\mathrm{La}_{0,8} \mathrm{Sr}_{0,2} \mathrm{MnO}_{3}$ e (e, f) $\mathrm{La}_{0,6} \mathrm{Sr}_{0,4} \mathrm{MnO}_{3}$. 

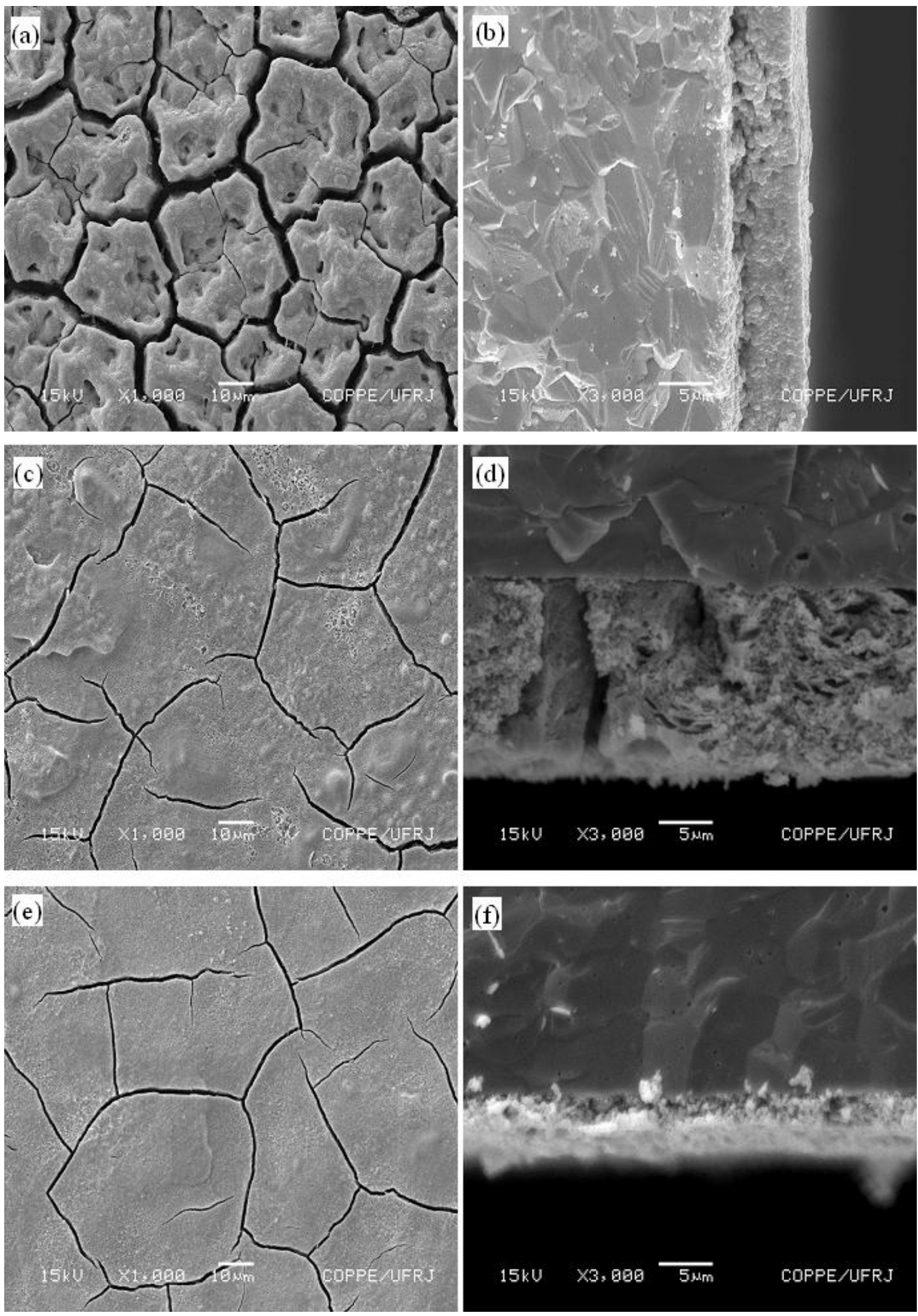

Figura 5: Imagens de microscopia eletrônica de varredura da superfície de seção transversal de filmes de LSM depositados em 8ZEI e tratados termicamente a $900^{\circ} \mathrm{C}$ : (a, b) $\mathrm{LaMnO}_{3}$, (c, d) $\mathrm{La}_{0,8} \mathrm{Sr}_{0,2} \mathrm{MnO}_{3}$ e (e, f) $\mathrm{La}_{0,6} \mathrm{Sr}_{0,4} \mathrm{MnO}_{3}$. 

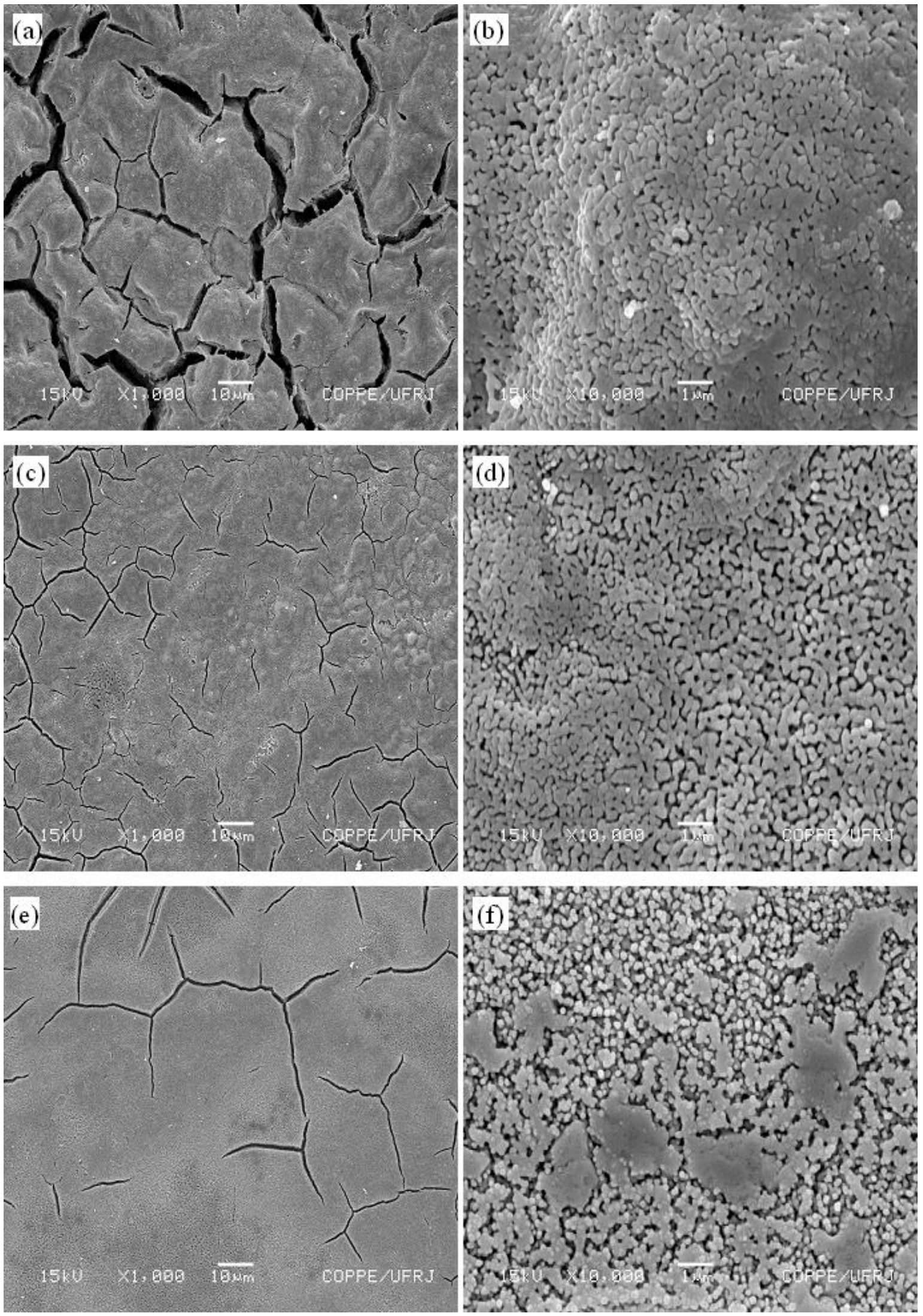

Figura 6: Imagens de microscopia eletrônica de varredura da superfície de filmes de LSM depositados em 8ZEI e tratados termicamente a $1000^{\circ} \mathrm{C}$ : (a, b) $\mathrm{LaMnO}_{3}$, (c, d) $\mathrm{La}_{0,8} \mathrm{Sr}_{0,2} \mathrm{MnO}_{3}$ e (e, f) $\mathrm{La}_{0,6} \mathrm{Sr}_{0,4} \mathrm{MnO}_{3}$. 

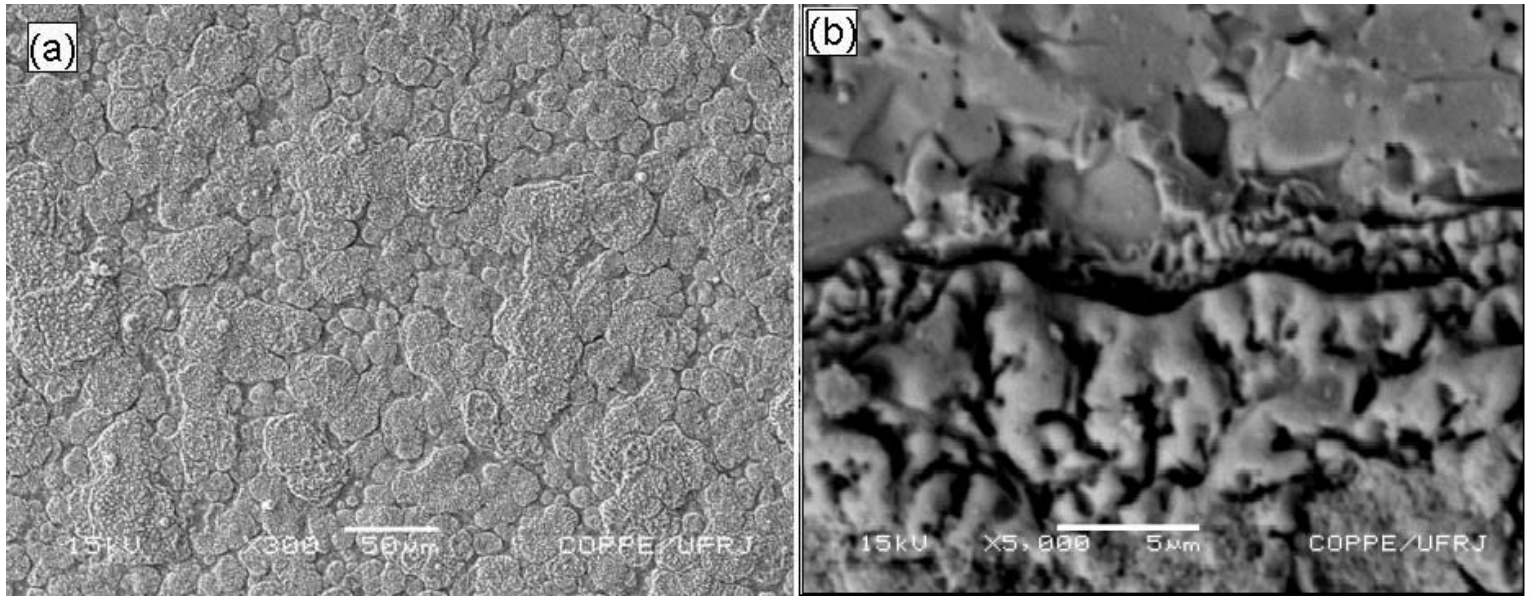

Figura 7: Imagens de microscopia eletrônica de varredura da (a) superfície e (a) secção transversal (interface) de filmes de LSM depositados em 8ZEI com fluxo de $1,0 \mathrm{ml} / \mathrm{min}$ e termicamente tratados a $900^{\circ} \mathrm{C}$ com taxa de aquecimento lenta.

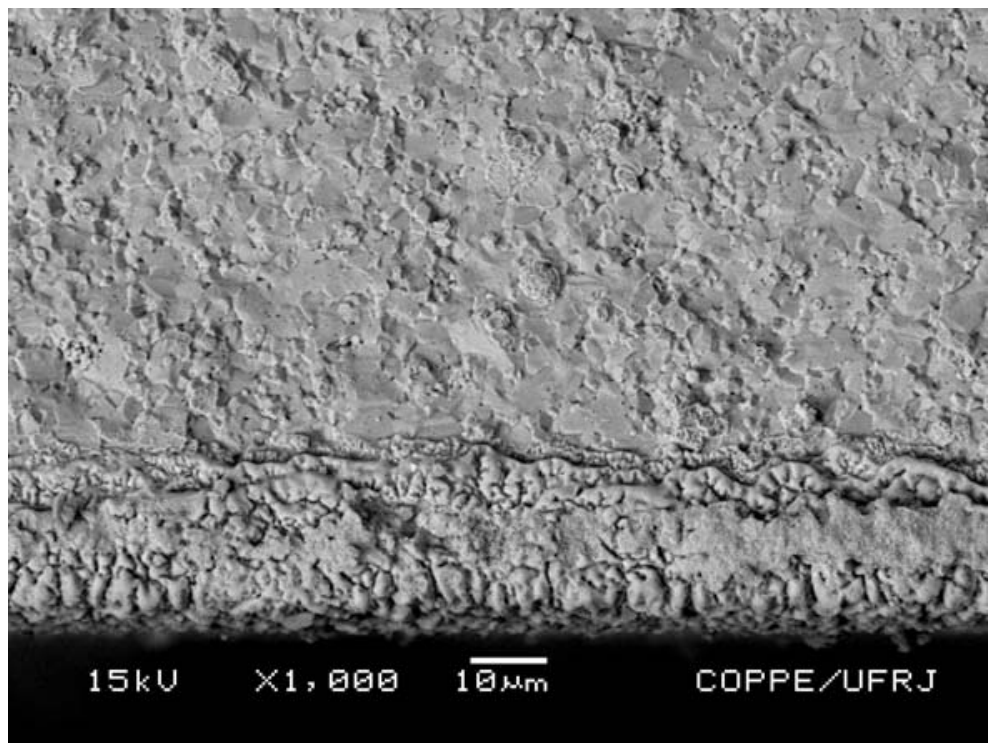

Figura 8: Imagem de microscopia eletrônica de varredura da secção transversal de filme LSM depositado em 8ZEI com fluxo de $1,5 \mathrm{ml} / \mathrm{min}$ e termicamente tratado a $900^{\circ} \mathrm{C}$ com taxa de aquecimento lenta.

\section{CONCLUSÕES}

Neste trabalho foram preparados filmes de LSM dopados com Sr nas concentrações de 0, 20 e $40 \%$ at. depositados em substratos de silício e 8ZEI pela técnica de spray-pirólise, os quais foram submetidos a tratamentos térmicos em temperaturas de 900 e $1000^{\circ} \mathrm{C}$ em atmosfera ambiente num período de 2 horas.

Os resultados obtidos revelaram que os tratamentos térmicos realizados propiciaram a formação das fases da perovskita em todos os filmes, sendo que nos filmes depositados em substratos de 8ZEI, foram observados picos referentes ao substrato.

As imagens de microscopia eletrônica de varredura mostraram que os filmes depositados em silício apresentam estrutura porosa e espessura apropriada. Os filmes depositados em 8ZEI, além de apresentarem porosidade, exibem maior aderência ao substrato.

O tratamento térmico propiciou a obtenção de filmes isentos de trincas quando adotadas taxas de aquecimento e resfriamento mais lentas tanto na etapa de deposição quanto na de tratamento térmico. 


\section{AGRADECIMENTOS}

Os autores agradecem ao CNPq (Projeto PaCOS-TI, aprovado no edital 018 do CT-Energia/CNPq 504.694/2004-9), FAPERJ e UENF pelo apoio financeiro.

\section{BIBLIOGRAFIA}

[1] GUO, R.S., WEI, Q.T., LI, H.L., et. al., "Synthesis and Properties of La0.7Sr0.3MO3 Cathode by gel Combustion”, Materials Letters, v. 60, pp. 261-265, 2006.

[2] TODOROVSKA, R., PETROVA, N., TODOROVSKY, D., et. al., "Spray-pyrolysis Deposition of $\mathrm{LaMnO}_{3}$ and $\mathrm{La}_{1 \_x} \mathrm{Ca}_{x} \mathrm{MnO}_{3}$ Thin Films”, Applied Surface Science, v. 252, pp. 3441-3448, 2005.

[3] TODOROVSKA, R., PETROVA, N., TODOROVSKY, D. "Spray Pyrolysis Deposition of YSZ and YSZ-Pt Composite Films”, Applied Surface Science, v. 177, pp. 613-621, 2005.

[4] LIM, D.P., LIM, D.S., OH, J.S., et. al., "Influence of post-treatments on the Contact Resistance of plasma-sprayed $\mathrm{La}_{0.8} \mathrm{Sr}_{0.2} \mathrm{MnO}_{3}$ coating on SOFC Metallic Interconnector”, Surface \& Coatings Technology, v. 200, pp. 1248-1251, 2005.

[5] VENANCIO, S.A., RABELO, S.S, PAES JR., H.R., "Influência das Condições de Processamento Térmico nas Propriedades Elétricas e Estruturais de Filmes de Manganita de Lantânio Dopados com Estrôncio”, In: 49 Congresso Brasileiro de Cerâmica, São Pedro, SP, Brasil, pp. 6-9 Junho 2005.

[6] GAUDON, M., ROBERT, C.L., ANSART, F., et. al., "Preparation and characterization of La a $_{1}$ ${ }_{x} \mathrm{Sr}_{\mathrm{x}} \mathrm{MnO}_{3+\delta}$ powder by sol-gel Processing”, Solid State Sciences, v. 4, pp. 125-133, 2002.

[7] SENGUTTUVAN, T.D., SAMANTA, S.B., SOOD, K.N., et. al., "Phases in copper-stabilized Zirconia Solid Oxide Fuel Cells Anode Material”, Materials Chemistry and Physics, v. 95, pp. 197-201, 2006.

[8] GHARBAGE, B., MANDIER, F., LAURET, H., et. al., "Electrical properties of $\mathrm{La}_{0,5} \mathrm{Sr}_{0,5} \mathrm{MnO}_{3}$ thin films”, Solid State Ionics, v. 82, pp. 85-94, 1995. 